\title{
The effect of coal bottom ash (CBA) on mechanical and durability characteristics of concrete
}

\author{
Khan R A* and Ganesh A
}

\author{
Department of Civil Engineering, Dr B R Ambedkar National Institute of Technology Jalandhar \\ * Corresponding Author : rizwankhan1@gmail.com
}

\begin{abstract}
The present paper would contribute to the efforts being made in the field of concrete technology towards development of concretes possessing good strength and durability properties along with economic and ecological advantage. In the present study it was found that with increase in amount of coal bottom ash, standard consistency, initial and final setting time increase at the same time workability of concrete decreases. Early age strength is less for bottom ash concrete compare to control mix, but as the age increases they show good improvement in strength due to pozzalanic reaction. Optimum dosage is observed to be $10 \%$ Grinded Bottom Ash (GBA) which shows about $14 \%$ more strength compared to control mix at 56 days. Also $20 \%$ replacement by GBA gives results comparable to control concrete. GBA concrete shows more resistance to acid attack compared to Original Bottom Ash (OBA). Mix M7 with 30 \% replacement by GBA shows highest resistance to acid attack. With the increase in amount of bottom ash water absorption capacity of concrete increases, also as the age increases for all the mix water absorption capacity decreases. It was also found that at optimum dosage i.e at 10\% replacement of cement with GBA it is also economical and also less amount of $\mathrm{CO}_{2}$ is emitted that mean it is also environmental friendly compared to control mix.
\end{abstract}

Key words: Coal Bottom Ash, Workability, Mechanical, Durability.

\section{Introduction}

Natural resources of aggregate, due to high consumption in construction fields, are getting depleted rapidly. Therefore, in the present conditions of inadequate resources of aggregate and development in concrete industry, it becomes crucial and necessary to detect ideal substitute material in durable concrete for aggregate. The environmentally-friendly solution is to use lowcost industrial residues or solid wastes in the production of concrete. In so doing, in spite of a decrease in the amount of industrial wastes sent to landfills, the impacts of the depletion of natural resources, and sever environmental hazards, this is a positive advance in sustainable development and opens new market opportunities. Bottom ash (BA) is one of the renowned industrial wastes produced at the bottom of coal furnaces. It is originated from agglomerated ash particles that are not finer and lighter to be found in the flue gasses. The chemical composition of BA includes heavy metals and arsenic. Due to this fact, the stockpiled piles of BA in ponds pose health hazards to human and the environment by spreading hazardous components and contaminating adjacent soil and underground water. Therefore, it becomes essential to recycle effectively and reuse BA due to deficiency of natural resources, economic problems and enormous negative impacts on the environment (Nikbin et al., 2016). BA is produced by combustion of coal. BA before and after being grounded was used as replacement of cement and its physical and chemical properties were studied, it was found that compressive strength of mortar containing $20-30 \%$ of BA as cement replacement was much less than that of cement mortar at all ages, but at 60 days BA concrete has more strength (Jaturapitakkul and Cheerarot, 2003). Grinded BA for different periods was used as replacement of cement and its mechanical properties, ecological and economical substation was studied. It was found that usage of BA in concrete industry help in reducing energy demand as well as $\mathrm{CO}_{2}$ emission; it also reduces the price of concrete by $10 \%$ (Bajare et al., 2013). Utilization of BA as fine and coarse aggregates in high-strength concrete was studied. Firstly, the chemical and physical 
characteristics of BA particles, such as chemical compositions, specific gravity and SEM images, were investigated. Further experiments were conducted by replacing fine and coarse BA with normal sand and gravel varying in percentages. The effect of fine and coarse BA on the flow characteristics and density of concrete mixture was investigated in the aspect of particle shapes and paste absorption of BA. Mechanical properties, such as compressive strengths and modulus of elasticity and flexural strength of high-strength concrete with BA were evaluated. It was found that the slump flow of fresh concrete was slightly decreased when coarse BA was replaced $100 \%$ of normal coarse aggregates, while fine BA did not affect the slump flow. Moreover, it also showed that both of fine and coarse BA aggregates had more influence on the flexural strength than compressive strength. Flexural strength of concrete almost linearly decreased as the replacement ratio of the fine and coarse BA was increased (Kim and Lee, 2011; Kim et al., 2014). Investigations were carried out on the use of BA waste as sand replacement and cement with fly ash. Concrete specimens were prepared incorporating 0, 20, 50, 75 and 100\% of BA replacing sand and $20 \%$ of coal fly ash by mass, as a substitute for Ordinary Portland cement. Results revealed that concrete workability reduced when BA content increased replacing sand. On the other hand, at the early age of 28 day, no significant effect was observed in compressive, flexural and tensile strengths of all concrete samples. After curing at 91 and 180 day ages, compressive strength of both the experimental and control concrete samples increased significantly but remained almost similar. However, flexural and splitting tensile strengths of the experimental mix containing $75 \%$ BA and $20 \%$ fly ash exceeded much more than the control sample. Moreover, drying-shrinkage of experimental concrete mixtures containing 50\%, 75\% and 100\% BA and 20\% fly ash was lower than the control mix. It is concluded that those experimental concrete mixes can be used in several structures (foundations, sub-bases, pavements, etc.) which will minimize the cost, energy and environmental problems to a great extent (Rafieizonooz et al., 2016). Influence of the use of coal bottom ash (CBA) as a replacement for natural fine aggregates on the properties of concrete in the fresh state is also studied by the researcher. Tests for water loss through bleeding and the determination of the setting times and plastic shrinkage, were carried out in order to evaluate the material in the presence of BA, as well as on the water consumption of concretes produced with BA is also discussed. The results showed that in the fresh state the concretes produced with the BA are susceptible to water loss by bleeding and the higher the percentage of BA used as a natural sand replacement the lower the deformation through plastic shrinkage. With increase in quantity of BA there is a slight delay for maximum temperature peak to be reached, the results also showed that the setting time is affected by the presence of BA in the concrete (Andrade et al., 2009). Fresh properties of concrete like bleeding, workability, hardened properties like compressive test, splitting tensile test, modulus of elasticity, chemical resistance, density of concrete permeable pore space and water absorption, $\mathrm{X}$-ray diffractogram, and SEM morphology of concrete containing BA as fine aggregate were studied, workability of BA concrete was found to decrease on use of CBA, water loss from bleeding decreased, permeable pore space increased in early age and reduced with the progress of curing age, water loss through air drying increases up to $50 \%$ replacement and from $75 \%$ it decreases, compressive strength reduces in early age and after 28 days curing strength increases, splitting tensile strength of concrete improved at all the curing ages on use of CBA as fine aggregate. (Siddique et al., 2014; Siddique, 2013; Singh and Siddique, 2014). Strength and drying shrinkage of concretes with the natural sand replaced with furnace BA by mass were studied at fixed water cement ratios and fixed slump ranges. The results showed that, at fixed water cement ratios, the compressive strength and the drying shrinkage decreases with the increase of the furnace BA sand content. However, at fixed workability, the compressive strength was comparable with that of the control concrete, while the drying shrinkage increased with the increase of the furnace BA content beyond 30\% replacement level. Nevertheless, $30 \%$ of the natural sand can be beneficially replaced with the furnace BA without detrimentally affecting drying shrinkage properties of the concrete (Bai et al., 2005). Moisture kinetics aspects of composite granular material samples composed of natural sand and BA from thermoelectric power stations and the use of this material in the production of durable concretes, in relation to water transport, are discussed. The evaluations of the phenomenon of water absorption by 
capillarity and the loss of water through air drying until hygroscopic equilibrium were carried out; the results showed that due to the high porosity of BA, the water absorption by capillarity along with the absorption velocity were higher in the compositions with greater BA content. The values for moisture equilibrium from air drying, absorption from capillarity and sorptivity obtained in the hydroscopic equilibrium tests, carried out on the same samples after absorption, were also higher in the samples with BA. These samples also requited a longer drying time (Andrade et al., 2007). Pozzolanic properties of a CBA were investigated. Plain pastes containing equal amounts of calcium hydroxide and BA were prepared and analysed at different ages for their strength and the calcium hydroxide consumption, it was found that at early ages, BA does not react with calcium hydroxide. Its pozzolanic reaction proceeds slowly and accelerates gradually to become very interesting after 28 days and especially after 90 days. The strength activity indexes measured on mortars are sufficiently important to allow the use of BA in concrete. An adequate grinding improves the pozzolanic activity of the BA, when CBA is ground for $6 \mathrm{~h}$ in a laboratory ball mill; the 28-day strength activity index is increased by 27\% (Cheriaf et al., 1999). Properties of concrete made with Portland cement, nine mixtures with $12.5 \%, 25 \%$ and $50 \%$ of replacement of cement by fly ash, rice husk ash and limestone filler; two with $(12.5+$ $12.5) \%$ and $(25+25) \%$ of fly ash and rice husk ash. All the mixtures were prepared with water/binder ratios of $0.35,0.50$, and 0.65 . The results show that the pozzolanic and physical effects have increased as the mineral addition increased in the mixture, being higher after 91 days than after 28 days. When the results for the same strength values are compared, it was observed that the filler effect increased more than the pozzolanic effect. The pozzolonic effect was stronger in the binary and ternary mixtures prepared with rice husk ash in proportions of $25 \%$ or higher. The binary mixtures of rice husk ash showed better performance than the fly ash material, although the ternary mixtures have reached better overall results (Isaia et al., 2003). Physical, chemical, mineralogical and thermal properties of the cenospheres obtained from an ash lagoon. Cenospheres quantity depends on the carbon and iron contents present in the ash. Cenospheres are being used in different industrial applications, mainly due to their low density, high strength, and good thermal properties. Results have shown that Alumina and quartz are the most predominant minerals present in the cenosphere sample. These particles are noticed to be almost uniform in size (Kolay and Singh, 2001). BA was used up to $25 \%$ as a partial substitute for the Portland cement. In order to be able to reduce the unburned carbon content, CBA was treated by three different processes (particle size classification, heavy medium separation and electrostatic separation). Results show that compared to other pre-treatment methods such as the heavy medium separation and electrostatic separation methods, the crushing-screening method was found to be a more useful method for lowering the carbon content of the CBA. Compressive and flexural strengths of specimens cured at 56 day increase with increasing amount of ash replacement up to 15\%, the maximum substitution rate of CBA was determined as $10 \%$. When $10 \%$ of CBA is replaced by cement, the compressive strength of CBA-concrete increases (Kurama and Kaya, 2008; Kurama et al., 2009).

Study of the literature shows that not much work has been reported on replacement of cement with BA. So in this paper we tried to study the effect of BA on mechanical and durability properties of concrete, as well as the economical and ecological study were done to know how much cost and $\mathrm{CO}_{2}$ emission is reduced.

\section{Experimental procedures}

\subsection{Materials}

Ordinary Portland cement (OPC) from a single lot was used throughout the course of the investigation. The physical properties of the cement were determined from various tests conforming to Indian Standard IS: 1489-1991(Part-1). All the tests were carried out as per recommendations of IS: 4031-1988. Cement was carefully stored to prevent deterioration in its properties due to contact with the moisture. 
Crushed angular granite from a local source was used as coarse aggregate. River sand was used as fine aggregate. The specific gravity and fineness modulus was 2.55 and 2.94 respectively and it belongs to zone II of grading as shown in Fig.1.

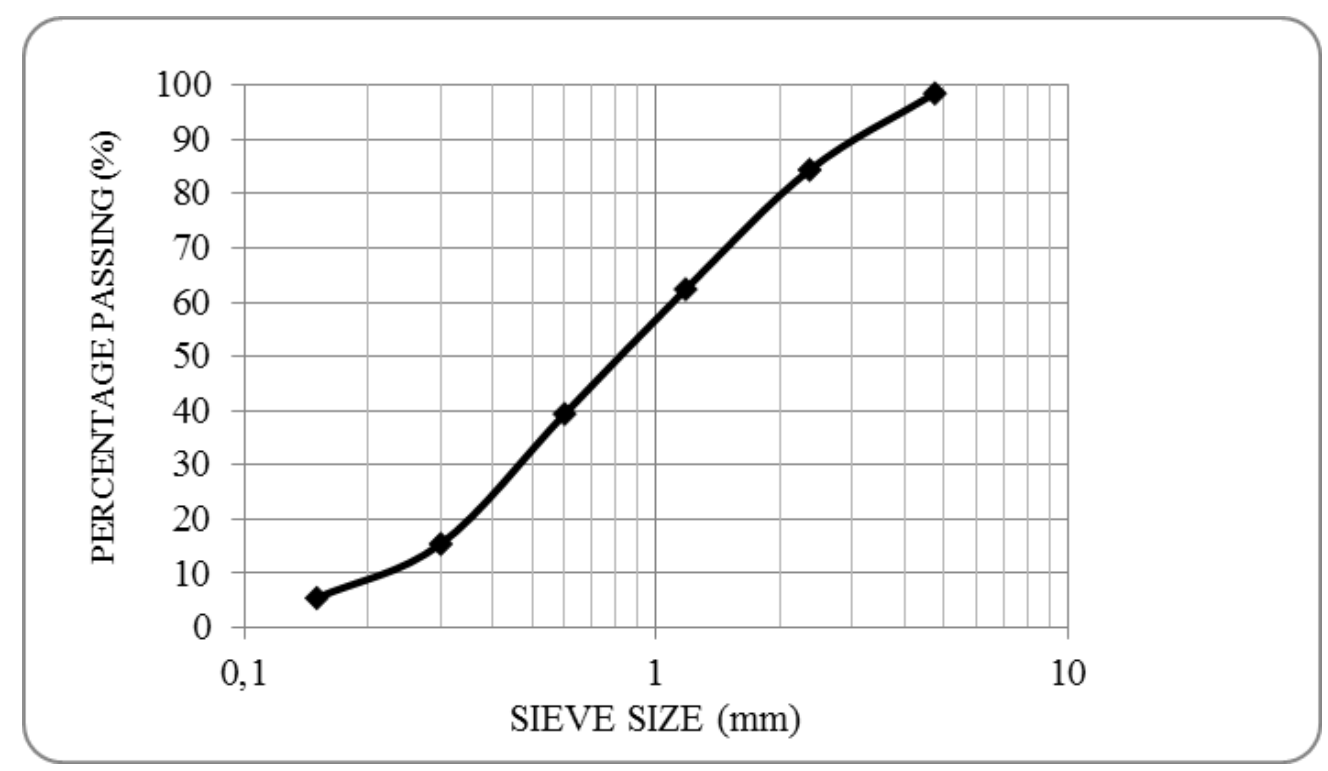

Fig 1. Sieve analysis of fine aggregates.

BA from nearby cement factories is used in this study. In this study we used two types of BA, Original bottom ash (OBA) without grinding is used in first set, BA that is grinded in Los Angeles abrasion test machine for 30 minutes is used in second test. Sieve analysis is carried out for both OBA and grinded bottom ash (GBA) and the difference is shown in Fig.2.

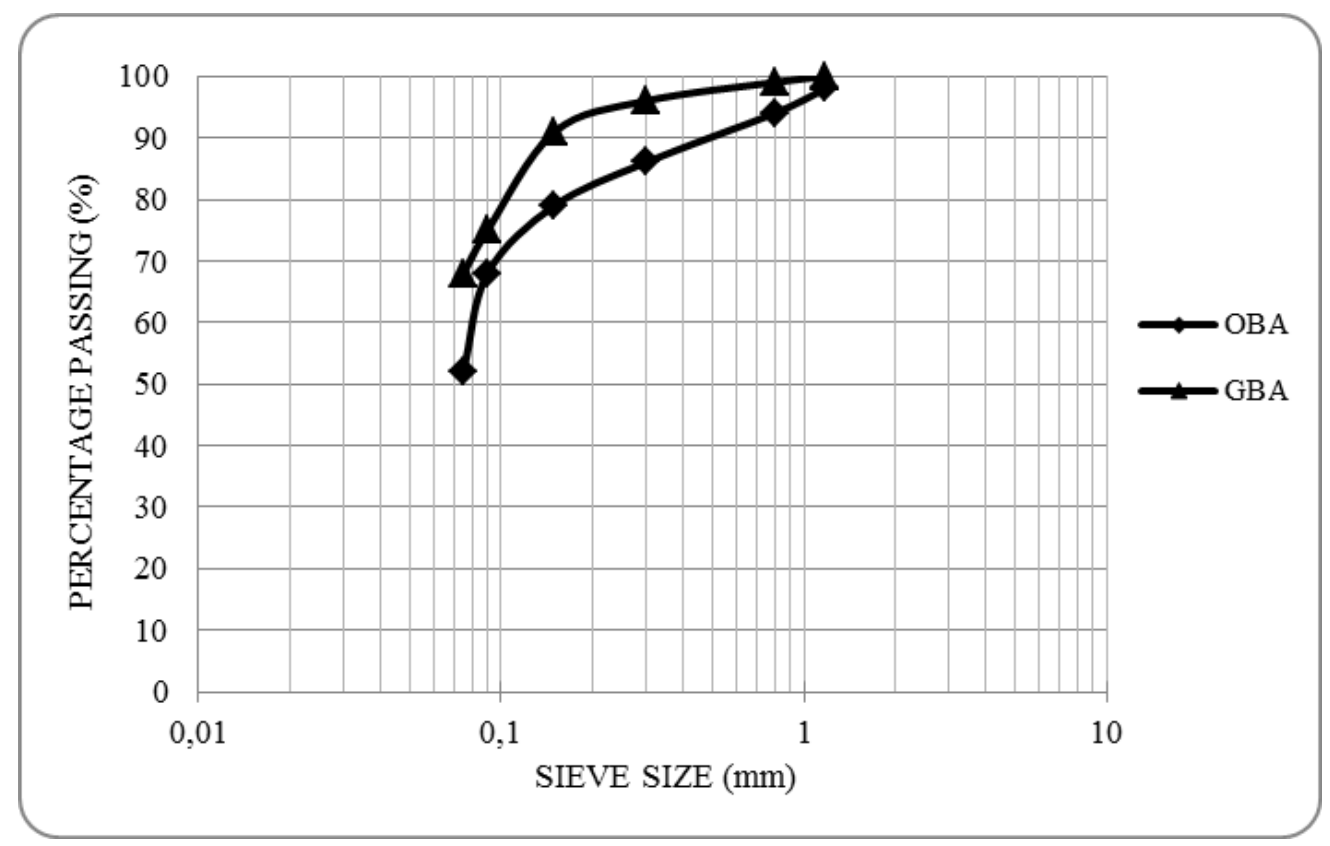

Fig 2. Comparison between OBA and GBA using sieve analysis taking 100gms of each.

\subsection{Preparation of mixes}

Different mixes were prepared and compared with control mix. Mix proportions are shown in Table 1.The mix design has been prepared as per Bureau of Indian standards guidelines IS : 10262-2009. 
Table 1. Mix proportion per $\mathbf{m}^{3}$.

\begin{tabular}{cccccccc}
\hline Mix & $\begin{array}{c}\text { Cement } \\
\left(\mathrm{kg} / \mathrm{m}^{3}\right)\end{array}$ & $\begin{array}{c}\text { OBA } \\
\left(\mathrm{kg} / \mathrm{m}^{3}\right)\end{array}$ & $\begin{array}{c}\text { GBA } \\
\left(\mathrm{kg} / \mathrm{m}^{3}\right)\end{array}$ & W/B & $\begin{array}{c}\text { Water } \\
\left(\mathrm{kg} / \mathrm{m}^{3}\right)\end{array}$ & $\begin{array}{c}\text { Fine Aggregate } \\
\left(\mathrm{kg} / \mathrm{m}^{3}\right)\end{array}$ & $\begin{array}{c}\text { Coarse Aggregate } \\
\left(\mathrm{kg} / \mathrm{m}^{3}\right)\end{array}$ \\
\hline \hline M1 & 438 & 0 & 0 & 0.45 & 198 & 630.89 & 1099.3 \\
M2 & 394.2 & 43.8 & 0 & 0.45 & 198 & 630.89 & 1099.3 \\
M3 & 350.4 & 87.6 & 0 & 0.45 & 198 & 630.89 & 1099.3 \\
M4 & 306.6 & 131.4 & 0 & 0.45 & 198 & 630.89 & 1099.3 \\
M5 & 394.2 & 0 & 43.8 & 0.45 & 198 & 630.89 & 1099.3 \\
M6 & 350.4 & 0 & 87.6 & 0.45 & 198 & 630.89 & 1099.3 \\
M7 & 306.6 & 0 & 131.4 & 0.45 & 198 & 630.89 & 1099.3 \\
\hline
\end{tabular}

\section{Results and discussion}

\subsection{Workability}

Workability is considered to be that property of plastic concrete which indicates its ability to be mixed, handled, transported and most importantly, placed with a minimum loss of homogeneity. More precisely, it defines that it can be fully compacted with minimum energy input. There should be no sign of any segregation or bleeding in a workable concrete. The workability of all the mixes of concrete used in this work was controlled by conducting slump test. W/B ratio was kept constant 0.45 for all the concrete mixes. The workability results of different concrete mixes were shown in Table 2. It shows that as the replacement of cement with BA increases, the workability of concrete mix decreases compared to control mix. It also shows that the addition of GBA decreases the workability more as compared to OBA. It may be due to the fact that GBA is finer than OBA which absorbs more water thereby reducing the workability.

Table 2. Workability values for different concrete mixes.

\begin{tabular}{ccc}
\hline Mix No & Description & Slump $(\mathrm{mm})$ \\
\hline \hline 1 & $100 \%$ OPC+0\%OBA+0\%GBA & 107 \\
2 & $90 \%$ OPC+10\%OBA+0\%GBA & 101 \\
3 & $80 \%$ OPC+20\%OBA+0\%GBA & 96 \\
4 & $70 \%$ OPC+30\%OBA+0\%GBA & 91 \\
5 & $90 \%$ OPC+0\%OBA+10\%GBA & 99 \\
6 & $80 \%$ OPC+0\%OBA+20\%GBA & 93 \\
7 & $70 \%$ OPC+0\%OBA+30\%GBA & 88 \\
\hline
\end{tabular}

\subsection{Standard consistency}

The object of conducting this test is to find out the amount of water to be added to the cement to get a paste of normal consistency, i.e., the paste of a certain standard solidity, which is used to fix the quantity of water to be mixed in cement before performing tests for setting time, soundness and compressive strength. The standard consistency test was carried out as per Indian standards IS:4031-Part4 1988. The standard consistency results for different mixes are given in Table 3. It was found that the standard consistency of paste increases with increase in replacement of cement with BA, this is even more when GBA is added. Standard consistency increases because BA absorbs water. GBA absorbs more water than OBA therefore standard consistency is more for GBA than OBA at the same cement replacement level.

Table 3. Standard consistency values of different mixes.

\begin{tabular}{ccc}
\hline Mix No & Description & Standard consistency (\%) \\
\hline \hline 1 & $100 \% \mathrm{OPC}+0 \% \mathrm{OBA}+0 \% \mathrm{GBA}$ & 31 \\
2 & $90 \% \mathrm{OPC}+10 \% \mathrm{OBA}+0 \% \mathrm{GBA}$ & 31 \\
3 & $80 \% \mathrm{OPC}+20 \% \mathrm{OBA}+0 \% \mathrm{GBA}$ & 32 \\
4 & $70 \% \mathrm{OPC}+30 \% \mathrm{OBA}+0 \% \mathrm{GBA}$ & 32 \\
5 & $90 \% \mathrm{OPC}+0 \% \mathrm{OBA}+10 \% \mathrm{GBA}$ & 32 \\
6 & $80 \% \mathrm{OPC}+0 \% \mathrm{OBA}+20 \% \mathrm{GBA}$ & 33 \\
7 & $70 \% \mathrm{OPC}+0 \% \mathrm{OBA}+30 \% \mathrm{GBA}$ & 34 \\
\hline
\end{tabular}




\subsection{Setting time}

In order that the concrete may be placed in position conveniently, it is necessary that the initial setting time of cement is not too quick and after it has been laid, hardening should be rapid so that the structure can be made use of as early as possible. The initial set is a stage in the process of hardening after which any cracks that may appear will not re-unite. The concrete is said to be finally set when it has obtained sufficient strength and hardness. The setting time for different mixes is given in Table 4. The mix to test setting time was prepared by taking the corresponding standard consistency values from the Table 3 . From the obtained standard consistency values the amount of water that is to be added to cement is calculated. As the replacement of cement with BA increases initial and final setting time increases. Initial and final setting time of cement depends on reaction of cement, so as the cement is replaced with BA the cement that is present for reaction decreases so it is taking more time for initial and final setting time. There is no much difference between adding OBA and GBA in both the cases they are nearly same.

Table 4. Setting time of different mixes.

\begin{tabular}{cccc}
\hline Mix No & Description & Initial setting time (minute) & Final setting time (minute) \\
\hline \hline 1 & 100\%OPC+0\%OBA+0\%GBA & 65 & 315 \\
2 & $90 \%$ OPC+10\%OBA+0\%GBA & 75 & 370 \\
3 & $80 \% \mathrm{OPC}+20 \%$ OBA+0\%GBA & 90 & 417 \\
4 & $70 \%$ OPC+30\%OBA+0\%GBA & 105 & 465 \\
5 & $90 \% \mathrm{OPC}+0 \% \mathrm{OBA}+10 \% \mathrm{GBA}$ & 75 & 360 \\
6 & $80 \% \mathrm{OPC}+0 \% \mathrm{OBA}+20 \% \mathrm{GBA}$ & 85 & 420 \\
7 & $70 \% \mathrm{OPC}+0 \% \mathrm{OBA}+30 \% \mathrm{GBA}$ & 105 & 470 \\
\hline
\end{tabular}

\subsection{Compressive strength test results of cement mortar}

The tests were conducted on cube of size $70.5 \mathrm{~mm} \times 70.5 \mathrm{~mm} \times 70.5 \mathrm{~mm}$. The cement sand mortar of the ratio $1: 3$ containing $(\mathrm{p} / 4+3) \%$ water was prepared and placed in moulds. Specimens were taken out from curing tank at the age of 7, 14, 28, 56 and 90 days of curing. Surface water was then allowed to drip down. Specimens were then tested on 200 tonnes capacity Compression Testing Machine. The position of cube while testing was at right angles to that of casting position. Axis of specimens was carefully aligned with the centre of thrust of the spherically seated plates. The load was applied gradually without any shock and increased at constant rate of $3.5 \mathrm{~N} / \mathrm{mm}^{2} /$ minute until failure of specimen takes place. The average of three samples was taken as the representative value of compression strength for each batch of mortar. The compressive strength was calculated by dividing the maximum compressive load by the cross sectional area of the cube specimens. Thus the compressive strength of different specimens was obtained. The test specimens are stored in place free from vibrations, in most air of at least $90 \%$ relative humidity and at a temperature of 27 degree centigrade for 24 hours from the time of addition of water to the dry ingredients. After this period, the specimens are marked and removed from the moulds and unless required for the test within 24 hours, immediately submerged in clean and fresh water and keep there until taken out just prior to test. The water or solution in which the specimens are submerged, are renewed every seven days and are maintained at a temperature of 27 degrees centigrade. The specimens are not to be allowed to become dry at any time until they have been tested. The specimens are tested at 7, 14, 28, 56 and 90 days of curing. The compressive strength test results of all the mixes at different curing ages are shown in Fig.3. In the first 28 days the strength of the BA cement mortar mix is less compared to control mix, because there is less cement in BA cement mortar mix compared to control mix. After 28 days the difference is gradually reduced because pozzolanic reaction starts and calcium hydroxide reacts with the BA and the strength increases. Cement mortar with GBA has more strength than that with OBA, because GBA is more fine compared to OBA (Fig.2). Cement mortar is dense in GBA compared to OBA so initial strength is more for GBA mortar. After 28 days pozzolanic reaction takes place, in GBA pozzolanic reaction is more compared to OBA because it is finer. 


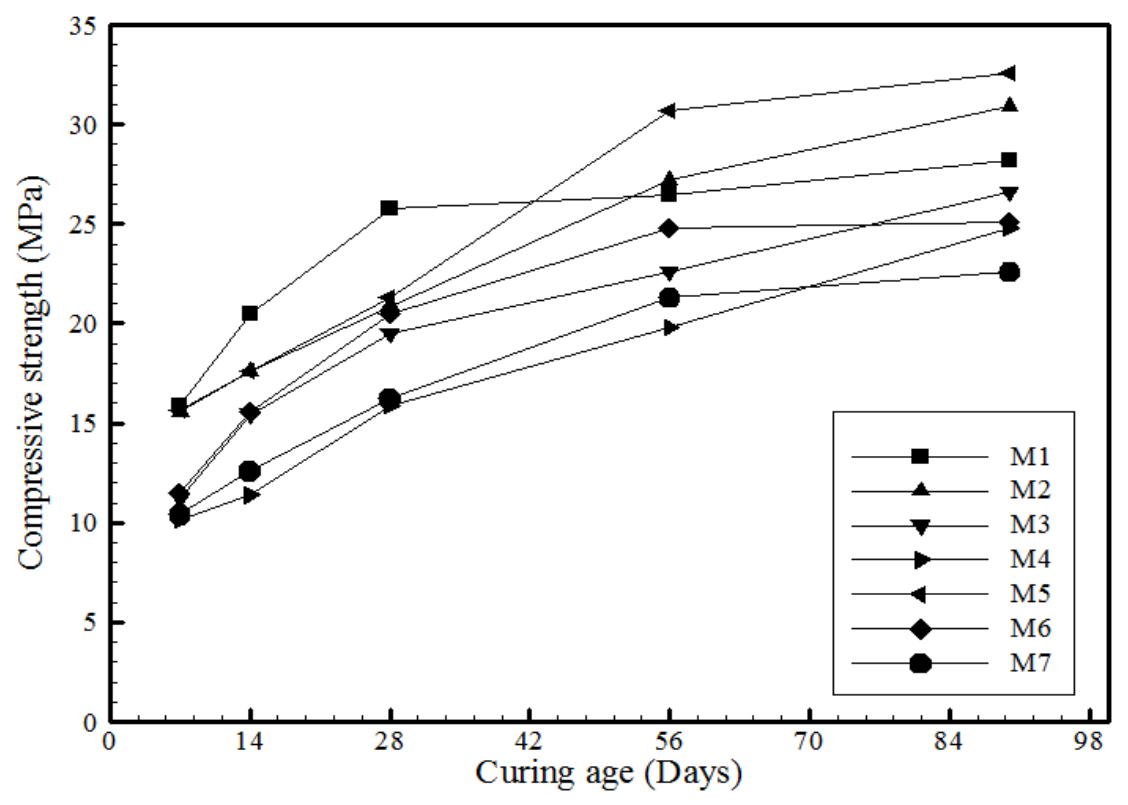

Fig 3. Compressive strength (MPa) results of all mortar mixes at different curing age.

\subsection{Compressive strength test results of concrete}

The tests were conducted on cube of size $150 \mathrm{~mm} \times 150 \mathrm{~mm} \times 150 \mathrm{~mm}$. Specimens were taken out from curing tank at the age of 7, 14, 28, 56 and 90 days of curing. Surface water was then allowed to drip down. Specimens were then tested on 200 tonnes capacity Compression Testing Machine (CTM). The position of cube while testing was at right angles to that of casting position. Axis of specimens was carefully aligned with the centre of thrust of the spherically seated plates. The load was applied gradually without any shock and increased at constant rate of 3.5 $\mathrm{N} / \mathrm{mm}^{2} /$ minute until failure of specimen takes place. The average of three samples was taken as the representative value of compression strength for each batch of concrete. The compressive strength was calculated by dividing the maximum compressive load by the cross sectional area of the cube specimens. Thus the compressive strength of different specimens was obtained. The test specimens are stored in place free from vibrations, in most air of at least $90 \%$ relative humidity and at a temperature of 27 degree centigrade for 24 hours from the time of addition of water to the dry ingredients. After this period, the specimens are marked and remove from the moulds and unless required for the test within 24 hours, immediately submerged in clean and fresh water or saturated lime solution and keep there until taken out just prior to test. The water or solution in which the specimens are submerged, are renewed every seven days and are maintained at a temperature of 27 degrees centigrade. The specimens are not to be allowed to become dry at any time until they have been tested. The specimens are tested at 7, 14, 28, 56 and 90 days of curing. The compressive strength test results of all the mixes at different curing ages are shown in Fig.4. It shows the variation of compressive strength of concrete mixes w.r.t control mix after 7, 14, 28, 56 and 90 days respectively. In the first 28 days strength of the BA concrete is very less compared to control mix concrete. In the first 28 days pozzolanic reaction doesn't start so early strength is due to the cement in the mix. In bottom ash concrete there is less cement compared to control mix so the strength of bottom ash concrete is less compared to control mix at 28 days. GBA is finer compared to OBA, so GBA is densely packed in concrete compare to OBA, so strength of GBA concrete is more than OBA concrete in the initial age. After 28 days BA concrete gains more strength compared to control mix and the difference between them is reduced because of pozzolanic reaction of bottom ash with calcium hydroxide. After 28 days GBA concrete gains more strength than OBA concrete because pozzolanic reaction is more in GBA concrete. At 56 days strength of the GBA concrete at $10 \%$ replacement (M5) is more than the control mix (M1) because of pozzolanic reaction. But at the same 10\% replacement OBA 
concrete (M2) is having less strength because it is coarser than GBA and having more voids than GBA, pozzolanic reaction in OBA is less. At 56 days strength of the M6 and M7 is less compared to M5, strength of M3 and M4 is less than M2, because pozzolanic reaction is slow and it requires calcium hydroxide to form pozzolanic reaction, since this mixes have less cement and more BA there is less calcium hydroxide available at that time so resulting in less strength.

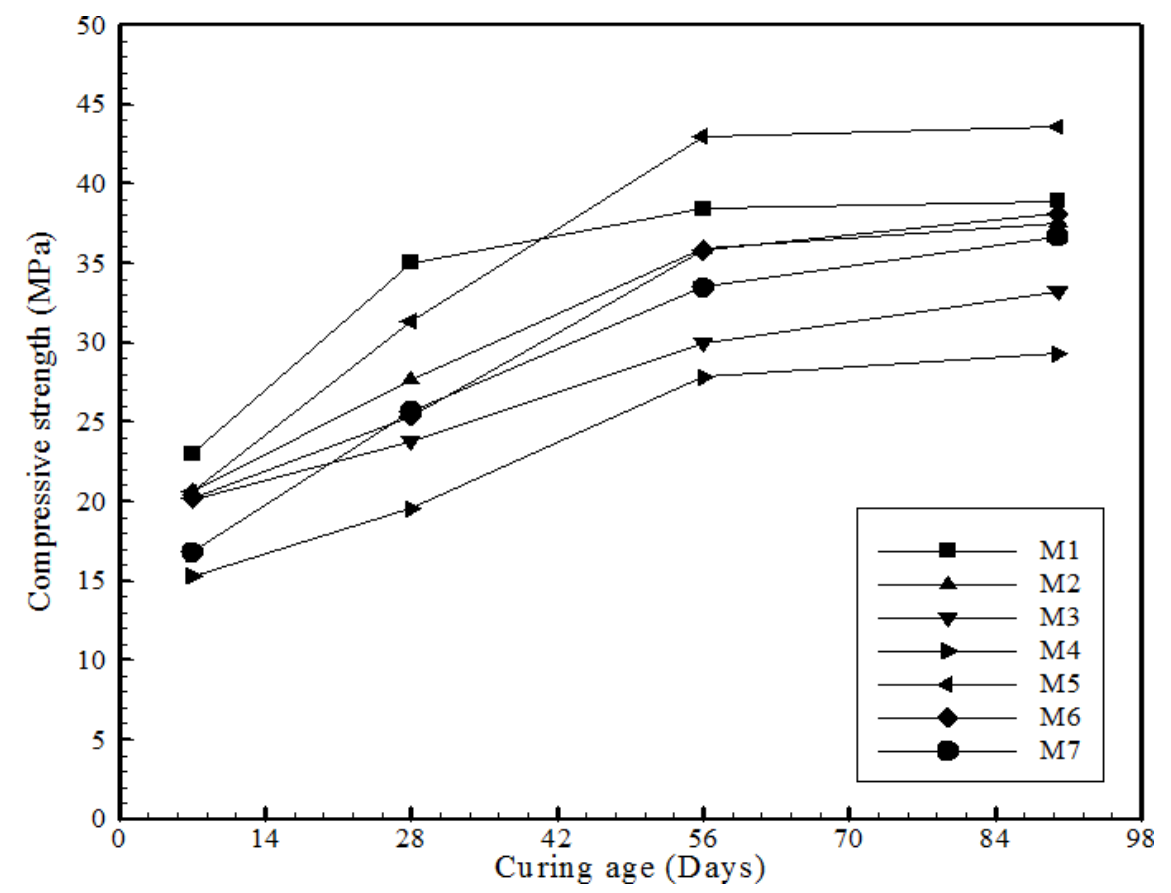

Fig 4. Compressive strength (MPa) results of concrete at different curing ages.

\subsection{Acid resistance test}

The concrete cubes of $150 \mathrm{~mm}$ size were cast for finding the mass loss due to the acid attack. The prepared cubes were cured in water for 28 days after which they were immersed in $1 \% \mathrm{H}_{2} \mathrm{SO}_{4}$ and the solution $\mathrm{pH}$ is maintained same $(\mathrm{pH} 2.0)$ for all the 90 days of curing. The initial mass and the mass of concrete specimens after the immersion period of 28, 56 and 90 days were measured for finding the mass loss due to the deterioration of concrete specimens. The average value of three specimens was considered for assessment. Table 5-8 show effect of acid attack on compressive strength of concrete. From table 5-8 it was observed that M7 mix is having highest resistance against weight loss in $1 \% \mathrm{H}_{2} \mathrm{SO}_{4}$ solution at all curing ages, and $\mathrm{M} 2$ mix is showing less resistance at all curing ages compared with control mix. It was observed that as the bottom ash content increases resistance against weight loss in $\mathrm{H}_{2} \mathrm{SO}_{4}$ increases. From above table it can also be observed that percentage loss in strength is less for M7. Further, itwas also found that concrete containing GBA has more resistance than OBA.

Table 5. Effect of acid attack on compressive strength of concrete after 28 days.

\begin{tabular}{|c|c|c|c|c|c|c|c|}
\hline \multirow[t]{2}{*}{$\begin{array}{l}\text { Sl. } \\
\text { No. }\end{array}$} & \multirow[t]{2}{*}{$\begin{array}{c}\text { Mix } \\
\text { Identity }\end{array}$} & \multicolumn{2}{|c|}{$\begin{array}{l}\text { Weight of cubes } \\
\text { before and after } \\
\text { immersion }(\mathrm{kg})\end{array}$} & \multirow[t]{2}{*}{$\begin{array}{l}\% \text { Loss in } \\
\text { weight }\end{array}$} & \multirow[t]{2}{*}{$\begin{array}{c}\text { Compressive } \\
\text { strength } \\
(\mathrm{N} / \mathrm{mm} 2)\end{array}$} & \multirow[t]{2}{*}{$\begin{array}{c}\text { Compressive } \\
\text { strength after acid } \\
\text { attack }(\mathrm{N} / \mathrm{mm} 2)\end{array}$} & \multirow[t]{2}{*}{$\begin{array}{l}\% \text { difference in } \\
\text { compressive } \\
\text { strength }\end{array}$} \\
\hline & & Before & After & & & & \\
\hline 1 & M1 & 2.579 & 2.544 & 1.35 & 38.45 & 32.62 & 15.16 \\
\hline 2 & M2 & 2.578 & 2.549 & 1.124 & 35.9 & 33.3 & 7.24 \\
\hline 3 & M3 & 2.501 & 2.478 & 0.92 & 30 & 28.6 & 4.66 \\
\hline 4 & M4 & 2.522 & 2.502 & 0.79 & 27.85 & 27.2 & 2.33 \\
\hline 5 & M5 & 2.583 & 2.555 & 1.084 & 43 & 39.4 & 8.37 \\
\hline 6 & M6 & 2.493 & 2.471 & 0.882 & 35.8 & 34.5 & 3.63 \\
\hline 7 & M7 & 2.4675 & 2.461 & 0.263 & 33.5 & 33.3 & 0.59 \\
\hline
\end{tabular}


Table 6. Effect of acid attack on compressive strength of concrete after 56 days.

\begin{tabular}{|c|c|c|c|c|c|c|c|}
\hline \multirow[t]{2}{*}{$\begin{array}{l}\text { Sl. } \\
\text { No. }\end{array}$} & \multirow[t]{2}{*}{$\begin{array}{c}\text { Mix } \\
\text { Identity }\end{array}$} & \multicolumn{2}{|c|}{$\begin{array}{l}\text { Weight of cubes } \\
\text { before and after } \\
\text { immersion }(\mathrm{kg})\end{array}$} & \multirow[t]{2}{*}{$\begin{array}{l}\text { \% Loss in } \\
\text { weight }\end{array}$} & \multirow[t]{2}{*}{$\begin{array}{c}\text { Compressive } \\
\text { strength } \\
(\mathrm{N} / \mathrm{mm} 2)\end{array}$} & \multirow[t]{2}{*}{$\begin{array}{c}\text { Compressive } \\
\text { strength after acid } \\
\text { attack }(\mathrm{N} / \mathrm{mm} 2)\end{array}$} & \multirow[t]{2}{*}{$\begin{array}{l}\text { \% difference in } \\
\text { compressive } \\
\text { strength }\end{array}$} \\
\hline & & Before & After & & & & \\
\hline 1 & M1 & 2.5725 & 2.532 & 1.574 & 38.9 & 31.4 & 19.25 \\
\hline 2 & M2 & 2.5825 & 2.5495 & 1.277 & 37.55 & 33.7 & 10.25 \\
\hline 3 & M3 & 2.545 & 2.5175 & 1.08 & 33.25 & 31.45 & 5.41 \\
\hline 4 & M4 & 2.5635 & 2.54 & 0.916 & 29.3 & 27.75 & 5.3 \\
\hline 5 & M5 & 2.6065 & 2.576 & 1.17 & 43.6 & 39.3 & 9.76 \\
\hline 6 & M6 & 2.4785 & 2.452 & 1.069 & 38.1 & 36.25 & 4.8 \\
\hline 7 & M7 & 2.547 & 2.528 & 0.746 & 36.7 & 36.1 & 1.6 \\
\hline
\end{tabular}

Table 7. Effect of acid attack on compressive strength of concrete after 90 days.

\begin{tabular}{|c|c|c|c|c|c|c|c|}
\hline \multirow[t]{2}{*}{$\begin{array}{l}\text { Sl. } \\
\text { No. }\end{array}$} & \multirow[t]{2}{*}{$\begin{array}{c}\text { Mix } \\
\text { Identity }\end{array}$} & \multicolumn{2}{|c|}{$\begin{array}{l}\text { Weight of cubes } \\
\text { before and after } \\
\text { immersion }(\mathrm{kg})\end{array}$} & \multirow[t]{2}{*}{$\begin{array}{l}\% \text { Loss in } \\
\text { weight }\end{array}$} & \multirow[t]{2}{*}{$\begin{array}{l}\text { Compressive } \\
\text { strength } \\
(\mathrm{N} / \mathrm{mm} 2)\end{array}$} & \multirow[t]{2}{*}{$\begin{array}{c}\text { Compressive } \\
\text { strength after acid } \\
\text { attack }(\mathrm{N} / \mathrm{mm} 2)\end{array}$} & \multirow[t]{2}{*}{$\begin{array}{l}\text { \% difference in } \\
\text { compressive } \\
\text { strength }\end{array}$} \\
\hline & & Before & After & & & & \\
\hline 1 & M1 & 2.5155 & 2.4445 & 2.8225 & 40.1 & 30.8 & 22.97 \\
\hline 2 & M2 & 2.631 & 2.5665 & 2.451 & 41.2 & 34.6 & 15.825 \\
\hline 3 & M3 & 2.575 & 2.5145 & 2.3495 & 37.6 & 34.5 & 8.244 \\
\hline 4 & M4 & 2.5865 & 2.5385 & 1.8557 & 34.2 & 31.4 & 7.94 \\
\hline 5 & M5 & 2.4315 & 2.3725 & 2.4264 & 44.45 & 37.9 & 14.68 \\
\hline 6 & M6 & 2.5385 & 2.4935 & 1.7727 & 41.5 & 38.25 & 7.83 \\
\hline 7 & M7 & 2.5465 & 2.523 & 0.9228 & 39.75 & 38.83 & 2.3 \\
\hline
\end{tabular}

Table 8. Percentage increase in the resistance of bottom ash concrete against the weight losses in comparison with ordinary concrete mixes.

\begin{tabular}{|c|c|c|c|c|}
\hline \multirow[b]{2}{*}{$\begin{array}{l}\text { Mix } \\
\text { Type }\end{array}$} & \multirow[b]{2}{*}{$\%$ of $B A$} & \multicolumn{3}{|c|}{$1 \% \mathrm{H}_{2} \mathrm{SO}_{4}$ solution } \\
\hline & & $\begin{array}{l}28 \text { days immersion } \\
\text { period }\end{array}$ & $\begin{array}{l}56 \text { days immersion } \\
\text { period }\end{array}$ & $\begin{array}{c}90 \text { days immersion } \\
\text { period }\end{array}$ \\
\hline M1 & $0.0 \%$ & -- & -- & -- \\
\hline M2 & $10 \%$ OBA & 0.226 & 0.297 & 0.371 \\
\hline M3 & $20 \%$ OBA & 0.43 & 0.494 & 0.473 \\
\hline M4 & $30 \%$ OBA & 0.56 & 0.658 & 0.966 \\
\hline M5 & $10 \%$ GBA & 0.266 & 0.404 & 0.396 \\
\hline M6 & $20 \% \mathrm{GBA}$ & 0.468 & 0.505 & 1.049 \\
\hline M7 & $30 \%$ GBA & 1.087 & .828 & 1.899 \\
\hline
\end{tabular}

\subsection{Water absorption test}

The concrete cubes of $100 \mathrm{~mm}$ size were cast for finding the water absorption by oven drying at $110^{\circ} \mathrm{C}$. The cubes of size $100 \mathrm{~mm}$ were cast and cured for 28, 56 and 90 days. After curing they are removed and surface dried and weight is measured it is taken as W1 and then it is dried in oven for 24 hours and weight is measured and again dried in oven until we get the constant weight that is taken as W2.

$$
\text { water absorbed }=\frac{w 1-w 2}{w 2} * 100
$$

The test results are shown in Table 9. It was observed that as the BA content increases the water absorption capacity of concrete is increased initially. At 90Days it was observed that BA concrete is absorbing less water than 28Days. 
Table 9. Water absorption of concrete.

\begin{tabular}{ccccc}
\hline \multirow{2}{*}{$\begin{array}{c}\text { Mix } \\
\text { Type }\end{array}$} & \% of BA & \multicolumn{3}{c}{ Water Absorption of concrete (\%) } \\
\cline { 3 - 5 } & & $\begin{array}{r}\text { 28 days immersion } \\
\text { period }\end{array}$ & $\begin{array}{c}\text { 56 days immersion } \\
\text { period }\end{array}$ & $\begin{array}{c}\text { 90 days immersion } \\
\text { period }\end{array}$ \\
\hline \hline M1 & $0.0 \%$ & 6.13 & 5.55 & 4.6 \\
M2 & 10\% OBA & 6.53 & 5.63 & 4.97 \\
M3 & 20\% OBA & 6.31 & 6.27 & 4.55 \\
M4 & 30\% OBA & 6.99 & 6.99 & 4.24 \\
M5 & 10\% GBA & 6.48 & 5.88 & 4.97 \\
M6 & 20\% GBA & 6.26 & 5.84 & 4.76 \\
M7 & 30\% GBA & 6.47 & 6.19 & 4.73 \\
\hline
\end{tabular}

\subsection{Economic and ecological study}

In this study the test results obtained from compression test are compared with the normal OPC concrete mix of that particular strength. The cement that is saved by adding BA is calculated. Cost of the cement that is saved is the economic benefit in case of replacement with ordinary BA. In case of GBA economic benefit is cost of cement that is saved minus grinding cost. From the compressive strength test results shown in Fig.4, comparing the results of BA concrete with control mix it was observed that $10 \%$ replacement of cement with GBA is showing good results so it has been taken as sample to check whether it is economical or not. In this study cost comparison of making 10\% GBA concrete with control mix is done. In this mix's amount of coarse aggregate, fine aggregate and water remains same so there is no effect of them on change in cost of concrete. Cost is affected only by change in cement content. Assuming the cost of transportation is same for both cement and BA the below calculations are done. Cost of one bag of cement is Rs.350 and each bag contains $50 \mathrm{~kg}$ of cement. Commercial electricity tariff is taken as Rs.7 per unit. CBA is grained in Los Angeles abrasion test machine or 30 minutes. Each time only $8 \mathrm{~kg}$ is taken for grinding. Power used by Los Angeles abrasion test machine is 1HP i.e it used one unit of power per one hour. In control mix $438 \mathrm{~kg}$ of cement was used. In $10 \%$ GBA replacement mix $394.2 \mathrm{~kg}$ of cement was used and $43.8 \mathrm{~kg}$ of GBA. From Table 10 it can be observed that for every one $\mathrm{m}^{3}$ of concrete we save Rs.287.44. 10\%GBA concrete was economical than control mix. Further emission of $\mathrm{CO}_{2}$ depends on the type of procedure used to make cement, generally we take 1 ton of cement production emits 1 ton of $\mathrm{CO}_{2}$. Carbon dioxide

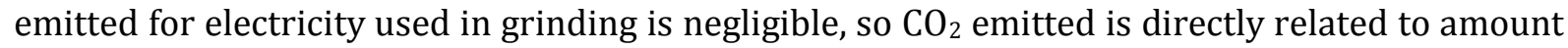
of cement used. From the study it was observed that for every one $\mathrm{m}^{3}$ of concrete $4.38 \mathrm{~kg}$ of $\mathrm{CO}_{2}$ emission is reduced per metre cube of concrete when GBA is used instead of cement.

Table 10. Cost (in Rs.) of mix per $\mathbf{m}^{3}$.

\begin{tabular}{ccc}
\hline & Control mix & $10 \%$ GBA mix \\
\hline \hline Cement used (kg) & 438 & 394.2 \\
Cost of cement (Rs) & 3066 & 2759.4 \\
GBA used (kg) & - & 43.8 \\
Cost for GBA (Rs) & - & 19.16 \\
Total Cost (Rs) & 3066 & 2778.56 \\
\hline
\end{tabular}

\section{Conclusions}

1. The results show that as the cement replacement with BA increases standard consistency increases. Addition of GBA increases the standard consistency more compared to OBA. Also initial and final setting time increases as the cement replacement with BA increases. It is observed that GBA and OBA show nearly same effect.

2. It was found that as the bottom ash content increases in the concrete workability decreases. For the same amount of bottom ash in GBA workability decreases more compared to OBA. 
3. It was observed that addition of BA reduces strength initially but later age strength was found to be more compared to control mix. Addition of GBA gives more strength compared to OBA concrete at all the ages. Addition of 10\% GBA shows more strength compared to control mix at 56 days and 90 days.

4. Optimum dosage is observed to be $10 \%$ GBA which shows about $14 \%$ more strength compared to control mix at 56 days. Also 20\% replacement by GBA gives results comparable to control concrete. It may be due to the fineness of GBA as compared to OBA.

5. The durability of concrete from the aspect of resistance to acid attack on concrete increases by replacing the cement with BA. It was observed that replacement of cement with GBA gives more resistance to acid attack as compared to OBA.

6. Concrete containing BA was found to absorb more water compare to ordinary concrete. As the curing age progress water absorption capacity of concrete before and after replacement with BA decreases.

7. It was observed that at optimum dosage i.e at $10 \%$ replacement of cement with GBA concrete is economical and $\mathrm{CO}_{2}$ emission also decreased that means it is environment friendly compare to control mix.

\section{References}

Andrade, L. B., Rocha, J. C., \& Cheriaf, M. (2007). Aspects of moisture kinetics of coal bottom ash in concrete. Cement and concrete research, 37(2), 231-241.

Andrade, L. B., Rocha, J. C., \& Cheriaf, M. (2009). Influence of coal bottom ash as fine aggregate on fresh properties of concrete. Construction and Building Materials, 23(2), 609-614.

Bai, Y., Darcy, F., \& Basheer, P. A. M. (2005). Strength and drying shrinkage properties of concrete containing furnace bottom ash as fine aggregate. Construction and Building materials, 19(9), 691697.

Bajare, D., Bumanis, G., \& Upeniece, L. (2013). Coal combustion bottom ash as microfiller with pozzolanic properties for traditional concrete. Procedia Engineering, 57, 149-158.

Cheriaf, M., Rocha, J. C., \& Pera, J. (1999). Pozzolanic properties of pulverized coal combustion bottom ash. Cement and concrete research, 29(9), 1387-1391.

IS 10262 2009. Concrete mix proprtioning guidelines, 9Bhadur Shah Zafar Marg, New Delhi, 110002.

IS 1489-1,1991. Specification for Portland pozzolona cement, Manak Bhavan, 9Bhadur Shah Zafar Marg, New Delhi, 110002.

IS 4031 Part-4 1988. Determination of consistency of standard cement paste, Manak Bhavan, 9Bhadur Shah ZafarMarg, New Delhi, 110002.

IS 4031,1988.Methods of Physical tests for hydraulic cement, Manak Bhavan, 9Bhadur Shah Zafar Marg, New Delhi, 110002.

Isaia, G. C., GASTALDInI, A. L. G., \& Moraes, R. (2003). Physical and pozzolanic action of mineral additions on the mechanical strength of high-performance concrete. Cement and concrete composites, 25(1), 69-76.

Jaturapitakkul, C., \& Cheerarot, R. (2003). Development of bottom ash as pozzolanic material. Journal of materials in civil engineering, 15(1), 48-53.

Kim, H. K., \& Lee, H. K. (2011). Use of power plant bottom ash as fine and coarse aggregates in highstrength concrete. Construction and Building Materials, 25(2), 1115-1122.

Kim, H. K., Jang, J. G., Choi, Y. C., \& Lee, H. K. (2014). Improved chloride resistance of high-strength concrete amended with coal bottom ash for internal curing. Construction and Building Materials, 71, 334343. 
Kolay, P. K., \& Singh, D. P. (2001). Physical, chemical, mineralogical, and thermal properties of cenospheres from an ash lagoon. Cement and Concrete Research, 31(4), 539-542.

Kurama, H., \& Kaya, M. (2008). Usage of coal combustion bottom ash in concrete mixture. Construction and building materials, 22(9), 1922-1928.

Kurama, H., Topcu, I. B., \& Karakurt, C. (2009). Properties of the autoclaved aerated concrete produced from coal bottom ash. Journal of materials processing technology, 209(2), 767-773.

Nikbin, I. M., Rahimi, S., Allahyari, H., \& Damadi, M. (2016). A comprehensive analytical study on the mechanical properties of concrete containing waste bottom ash as natural aggregate replacement. Construction and Building Materials, 121, 746-759.

Rafieizonooz, M., Mirza, J., Salim, M. R., Hussin, M. W., \& Khankhaje, E. (2016). Investigation of coal bottom ash and fly ash in concrete as replacement for sand and cement. Construction and Building Materials, 116, 15-24.

Siddique, R. (2013). Compressive strength, water absorption, sorptivity, abrasion resistance and permeability of self-compacting concrete containing coal bottom ash. Construction and Building Materials, 47, 1444-1450.

Siddique, R., Aggarwal, P., \& Aggarwal, Y. (2012). Influence of water/powder ratio on strength properties of self-compacting concrete containing coal fly ash and bottom ash. Construction and Building Materials, 29, 73-81.

Singh, M., \& Siddique, R. (2014). Strength properties and micro-structural properties of concrete containing coal bottom ash as partial replacement of fine aggregate. Construction and Building Materials, 50, 246-256. 